\title{
Commentary: Between the devil and the deep blue sea: A new palliation for high-risk neonates with hypoplastic left heart syndrome
}

\author{
Morgan L. Brown, MD, PhD, ${ }^{\mathrm{a}}$ and Francis Fynn-Thompson, $\mathrm{MD}^{\mathrm{b}}$
}

\footnotetext{
From the Departments of ${ }^{\mathrm{a}}$ Anesthesiology, Perioperative, and Pain Medicine, and ${ }^{\mathrm{b}}$ Cardiac Surgery, Boston Children's Hospital, Boston Mass.

Disclosures: Authors have nothing to disclose with regard to commercial support.

Received for publication April 21, 2019; accepted for publication April 22, 2019; available ahead of print May 27 , 2019.

Address for reprints: Morgan L. Brown, MD, PhD, Department of Anesthesia, Perioperative, and Pain Medicine, Boston Children's Hospital, 300 Longwood Ave, Boston, MA 02115 (E-mail: Morgan.brown@childrens. harvard.edu).

J Thorac Cardiovasc Surg 2019;158:e65-6

$0022-5223 / \$ 36.00$

Copyright (C) 2019 by The American Association for Thoracic Surgery

https://doi.org/10.1016/j.jtcvs.2019.04.067
}

In 1980, William Norwood reported his first successful first stage palliation for hypoplastic left heart syndrome (HLHS). ${ }^{1}$ Despite variations in technique, patients with HLHS undergoing the first-stage operation retain a significant risk of mortality perioperatively, with estimates of $7 \%$ to $39 \%$. $^{2}$ Much of the variation depends on center experience, but another important feature is inherent patient characteristics. Specific subgroups of neonates with HLHS have been identified as being at risk for mortality, including patient factors such as small size, prematurity, or a genetic syndrome. ${ }^{3}$ There are also high-risk anatomic subsets, including those patients with an intact atrial septum, right ventricular dysfunction, atrioventricular valve regurgitation, and the presence of left ventricular dependent coronaries. $^{3,4}$

What is the best option for patients who are at high risk for mortality when undergoing stage 1 procedure or hybrid procedure? If primary transplant appears to be the best longterm option, what is the best strategy to bridge these patients until a donor heart is available? Different approaches to these high-risk neonates have been suggested, including using a hybrid technique as a bridge to transplant or bridge to decision. ${ }^{5,6}$ A small case series by Philip and colleagues ${ }^{7}$ describes a novel approach: marrying a hybrid palliation, including placement of bilateral pulmonary artery bands, a patent ductus arteriosus stent, and an atrial septectomy, with the placement of a Excor pulsatile ventricular assist device (Berlin Heart Inc, The Woodlands, Tex) (from the right atrium to the main pulmonary artery). ${ }^{7}$ They were able to palliate these complex patients for several months (range, 56 to 162 days) with $100 \%$ 30-day survival and with 2 of 5 patients successfully transplanted. This is an early experience with limited follow-up. No patients in this series had clinically apparent cerebral vascular accidents, although the high risk of neurologic events has been well described

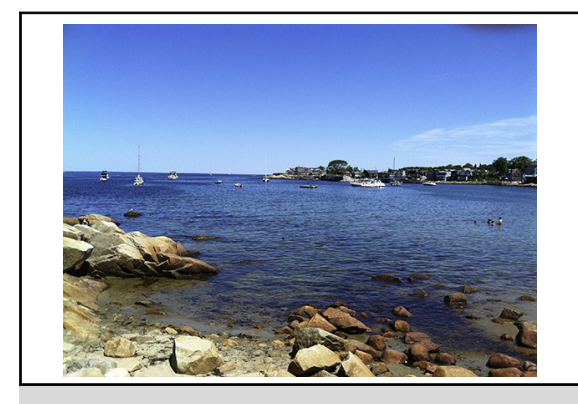

Between the devil and the deep blue sea.

\section{Central Message}

Neonates with HLHS and certain high-risk factors remain at high risk for mortality and cardiac transplantation following attempts at palliation. This report provides a novel strategy for palliation.

See Article page e59.

with the Excor, ${ }^{8}$ especially in patients with single ventricle anatomy.

Ultimately, neonates with HLHS and certain patient factors and anatomic features remain at very high risk for mortality following all attempts at primary palliation, as well as on the waitlist for cardiac transplantation. The authors and their entire team should be congratulated on their outcomes following this novel strategy that may provide another option to families and physicians stuck between the devil and the deep blue sea.

\section{References}

1. Norwood WI, Kirklin JK, Sanders SP. Hypoplastic left heart syndrome: experience with palliative surgery. Am J Cardiol. 1980;45:87-91.

2. Ohye RG, Sleeper LA, Mahony L, Newburger JW, Pearson GD, Lu M, et al. Comparison of shunt types in the Norwood procedure for single-ventricle lesions. N Engl J Med. 2010;362:1980-92.

3. Tabbutt S, Ghanayem N, Ravishnankar C, Sleeper LA, Cooper DS, Frank DU, et al. Risk factors for hospital morbidity and mortality after the Norwood procedure: a report from the pediatric heart network single ventricle reconstruction trial. J Thorac Cardiovasc Surg. 2012;144:882-95.

4. Vida VL, Bacha EA, Larrazabal A, Gauvreau K, Dorfman AL, Marx G, et al. Surgical outcome for patients with the mitral stenosis-aortic atresia variant of hypoplastic left heart syndrome. J Thorac Cardiovasc Surg. 2008;135:344-6.

5. Morray BH, Labers EL, Jones TK. Hybrid stage 1 palliation as a bridge to cardiac transplantation in patients with high-risk single ventricle physiology. Pediatr Transplant. 2018;22:e13307-14.

6. Nwankwo UT, Morell EM, Trucco SM, Morell VO, Kreutzer J. Hybrid strategy for neonates with ductal-dependent systemic circulation at high risk for Norwood. Ann Thorac Surg. 2018;106:595-601. 
7. Philip J, Reyes K, Ebraheem M, Gupta D, Fudge JC, Bleiweis MS. Hybrid procedure with pulsatile ventricular assist device for hypoplastic left heart syndrome awaiting transplantation. J Thorac Cardiovasc Surg. 2019;158:e59-61.
8. Jordan LC, Ichord RN, Reinhartz O, Humpl T, Pruthi S, Tjossem C, et al. Neurological complications and outcomes in the Berlin Heart EXCOR pediatric investigational device exemption trial. J Am Heart Assoc. 2015;4:e001429-39. 